2019-03-14

\title{
Acute myeloid leukaemia: an unusual cause of biliary strictures.
}

\author{
Beck, A
}

http://hdl.handle.net/10026.1/13538

10.1136/bcr-2018-227821

BMJ Case Reports

BMJ Publishing Group

All content in PEARL is protected by copyright law. Author manuscripts are made available in accordance with publisher policies. Please cite only the published version using the details provided on the item record or document. In the absence of an open licence (e.g. Creative Commons), permissions for further reuse of content should be sought from the publisher or author. 


\title{
Acute myeloid leukaemia: an unusual cause of biliary strictures
}

\author{
Adele Beck, ${ }^{1}$ Hannah Hunter, ${ }^{2}$ Simon Jackson, ${ }^{3}$ David Sheridan ${ }^{01,4}$
}

${ }^{1}$ University Hospitals Plymouth NHS Trust, Plymouth, UK 2Department of Haematology, University Hospitals Plymouth NHS Trust, Plymouth, UK ${ }^{3}$ Department of Radiology, University Hospitals Plymouth NHS Trust, Plymouth, UK ${ }^{4}$ Faculty of Medicine \& Dentistry, University of Plymouth, Plymouth, UK

Correspondence to Dr David Sheridan, david.sheridan@plymouth.ac.uk

Accepted 6 February 2019

Check for updates

(C) BMJ Publishing Group Limited 2019. No commercial re-use. See rights and permissions. Published by BMJ.

To cite: Beck A, Hunter $H$, Jackson $\mathrm{S}$, et al. BMJ Case Rep 2019;12:e227821. doi:10.1136/bcr-2018227821

\section{SUMMARY}

A 17-year-old man with no significant past medical history presented with a 2-week history of worsening jaundice, lethargy, anorexia and progressive right upper quadrant abdominal pain. There were no stigmata of chronic liver disease. Initial investigations were suggestive of cholangitis with large intrahepatic and extrahepatic bile duct strictures but otherwise normal hepatic and splenic appearances. A percutaneous transhepatic cholangiogram with the positioning of drains was performed to alleviate the obstructive jaundice. Within 2 weeks of the first presentation, full blood count revealed a significantly raised white blood count and a subsequent peripheral blood smear and bone marrow were consistent with a diagnosis of acute myeloid leukaemia. Chemotherapy was started after partial improvement of his obstructive jaundice. Complete morphological and cytogenetic remission was obtained 4 weeks after the first cycle of chemotherapy (half dose of daunorubicin and full dose of cytarabine, treated off trial) on control bone marrow. The patient remains in remission.

\section{BACKGROUND}

Acute myeloid leukaemia (AML) rarely presents with obstructive jaundice. A cholestatic picture in the context of AML is sometimes associated with chemotherapy. ${ }^{1}$ There are case reports of AML presenting as cholestatic jaundice as a result of hepatic sinusoidal infiltration, which usually resolves following cessation of chemotherapy. ${ }^{2}$ This case was an unusual presentation with large duct strictures, with no evidence of small duct obstruction or sinusoidal infiltration at liver biopsy.

Patients identified from previous case reports have presented with features suggesting a haematological diagnosis, such as anaemia, lymphadenopathy and splenomegaly. In this case, the presenting symptoms were of obstructive jaundice, with no overt features of AML, and circulating blasts were initially undetectable in peripheral blood samples at presentation.

\section{CASE PRESENTATION}

A 17-year-old man with no significant past medical history presented to the clinic with a 2 -week history of worsening jaundice, lethargy, anorexia and progressive right upper quadrant abdominal pain. History revealed no recreational drug use, herbal remedies or supplements, and there was no history of high-risk sexual behaviour or recent foreign travel.

Clinical examination showed marked jaundice without ascites, liver flap or stigmata of chronic liver disease. There was no palpable lymphadenopathy and evidence of hepatosplenomegaly.

He was admitted 1 week later with progressive right upper quadrant abdominal pain and deteriorating liver function tests.

\section{INVESTIGATIONS}

On first presentation, full blood count (FBC), differential cell count and clotting were normal. His liver function tests showed a mixed cholestatic and hepatitic picture with raised bilirubin $101 \mu \mathrm{mol} / \mathrm{L}$, alkaline phosphatase (ALP) 311 U/L, alanine transaminase (ALT) 536 IU/L, gamma-glutamyl transferase $446 \mathrm{IU} / \mathrm{L}$ and albumin $48 \mathrm{~g} / \mathrm{L}$. Serological testing for hepatitis $\mathrm{A}, \mathrm{B}, \mathrm{C}$ and $\mathrm{E}$ viruses, cytomegalovirus and Epstein-Barr virus was negative. Anti-nuclear antibodies (ANA), anti-neutrophil cytoplasmic antibodies, anti-smooth muscle antibodies and anti-mitochondrial antibodies were all negative. Immunoglobulins were normal. Abdominal ultrasound demonstrated a thick-walled and mildly dilated common bile duct (CBD) suggesting cholangitis, with intrahepatic bile duct dilatation (figure 1). The liver was smooth in outline and of normal echogenicity and the spleen was of normal size. Magnetic resonance cholangiopancreatography (MRCP) confirmed significant intrahepatic biliary duct dilatation lying proximal to a hilar stricture associated with soft tissue thickening as well as a CBD stricture and narrowing of the pancreatic duct (figure 2).

Two weeks after the first presentation, he developed a mild leukocytosis on FBC showing a total white count $8.6 \times 10^{9} / \mathrm{LL}$, haemoglobin concentration $138 \mathrm{~g} / \mathrm{L}$, platelet count $341 \times 10^{9} / \mathrm{L}$ and mean corpuscular volume (MCV) $81.0 \mathrm{fl}$. The differential count showed: neutrophils $2.2 \times 10^{9} / \mathrm{L}$, lymphocytes $6 \times 10^{9} / \mathrm{L}$, monocyte $0.0 \times 10^{9} / \mathrm{L}$, eosinophils $0.0 \times 10^{9} / \mathrm{L}$ and basophils $0.0 \times 10^{9} / \mathrm{L}$. A peripheral blood film was performed showing atypical and reactive lymphocytes (see figure 3 ). A second blood film was performed 2 days later, showing increasing numbers of atypical lymphoid cells, which looked more malignant and less reactive than those seen in the previous film.

Bone marrow aspirate was performed and was hypercellular and densely packed with medium-size and large-size blasts with vacuolation (see figure 4). Immunohistochemical analysis of the 


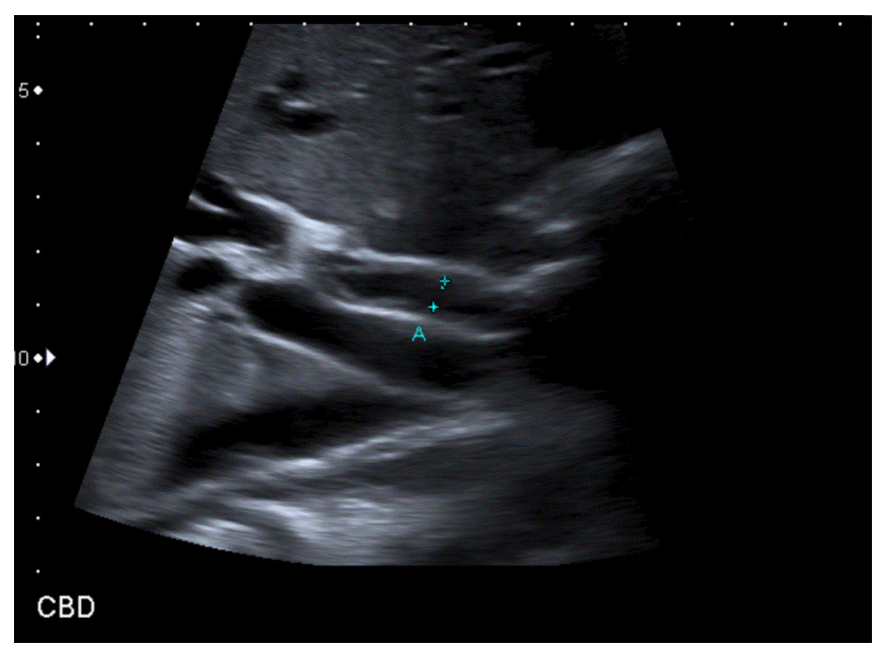

Figure 1 Abdominal ultrasound: intrahepatic bile duct thickening. CBD, common bile duct.

blast cells was positive for CD13, CD117 and myeloperoxidase. Chromosome and fluorescence in situ hybridization analysis showed a pericentric inversion of chromosome 16 and insertion of unknown material into the long arm of chromosome 4. This was consistent with a diagnosis of AML (WHO subtype inv[16] [p13.1q22]; CBFB-MYH11).

CT of the thorax, abdomen and pelvis was performed during the first cycle of chemotherapy to rule out fungal infection while the patient was neutropenic and septic. This confirmed the diagnosis of intrahepatic stricture with no abnormal liver architecture and appearance. There were no masses or significant lymphadenopathy.

Transjugular liver biopsy was performed following the first cycle of chemotherapy. An earlier biopsy was contraindicated by the obstructive jaundice and risk of bile leak. Examination of the portal tracts showed a mild, predominantly intrahepatocytic cholestasis and a mild chronic inflammatory cell infiltrate, which was lymphohistiocytic. There was no overt evidence of liver infiltration by acute myeloid leukaemia.

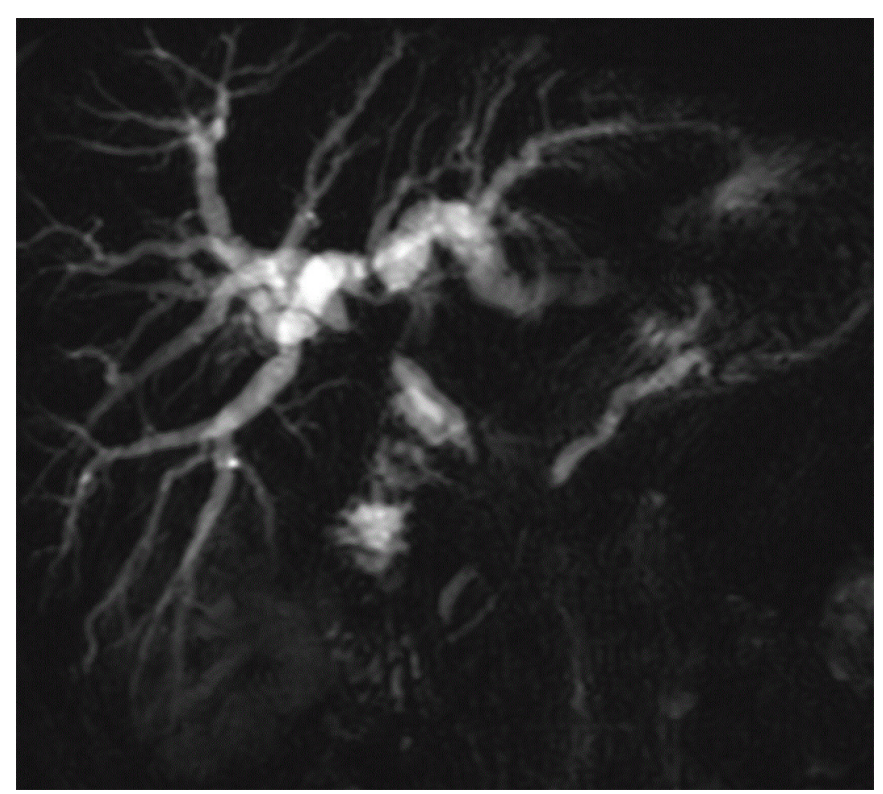

Figure 2 Magnetic resonance cholangiopancreatography prior to treatment: multifocal strictures with proximal hilar stricture.

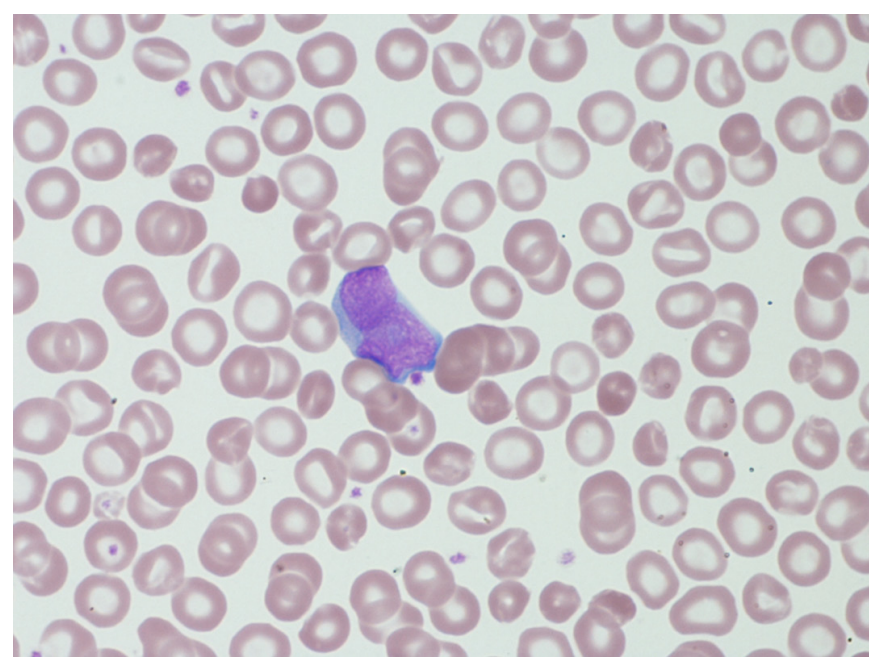

Figure 3 Blood film $\times 100$ hydroxyethyl starch (HES): atypical lymphoid cells.

\section{DIFFERENTIAL DIAGNOSIS}

In a 17-year-old male patient, a number of differential diagnoses are to be considered when presenting with obstructive jaundice, right upper quadrant pain and lethargy.

The detailed history taken on admission reduced the likelihood of any potential drug-induced liver injury. The viral hepatitic screen returned negative.

Septic cholangitis and choledocolithiasis were excluded by the absence of raised inflammatory markers, negative microbiology and absence of stones on MRCP.

ANA, cytoplasmic antineutrophil cytoplasmic antibodies (cANCA), perinuclea anti-neutrophil cytoplasmic antibodies (pANCA), anti-smooth muscle antibodies and anti-mitochondrial antibodies, as well as immunoglobulins, were negative.

The liver biopsy performed after the first cycle showed no evidence of autoimmune liver disease, such as autoimmune hepatitis, primary sclerosing cholangitis (PSC), primary biliary cirrhosis or IgG4 cholangitis.

Cholangiocarcinoma rarely presents in this age group, particularly in the absence of PSC. His CA19.9 marker was normal.

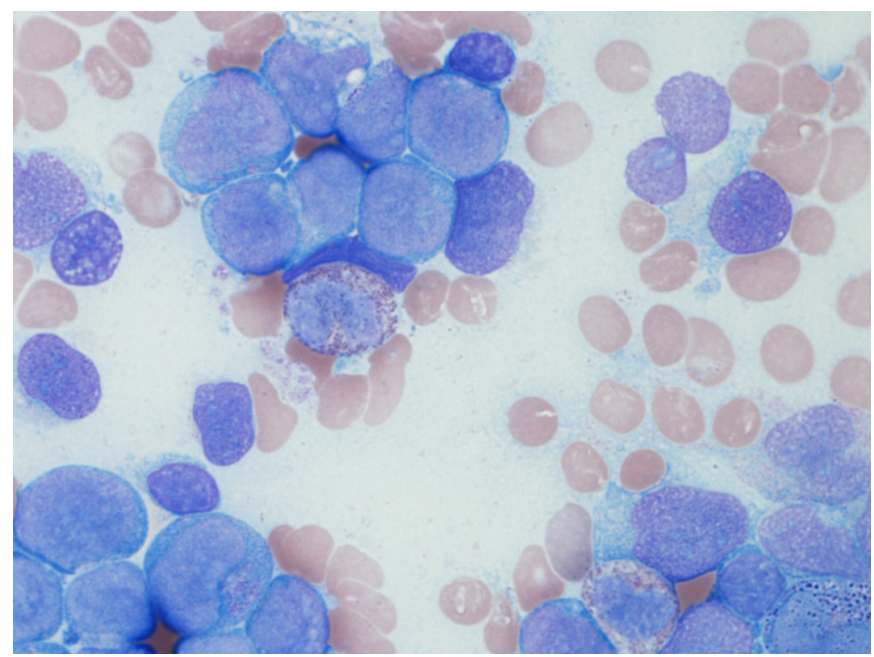

Figure 4 Bone marrow $\times 100$ hydroxyethyl starch (HES): densely packed large-size blasts with vacuolation. 


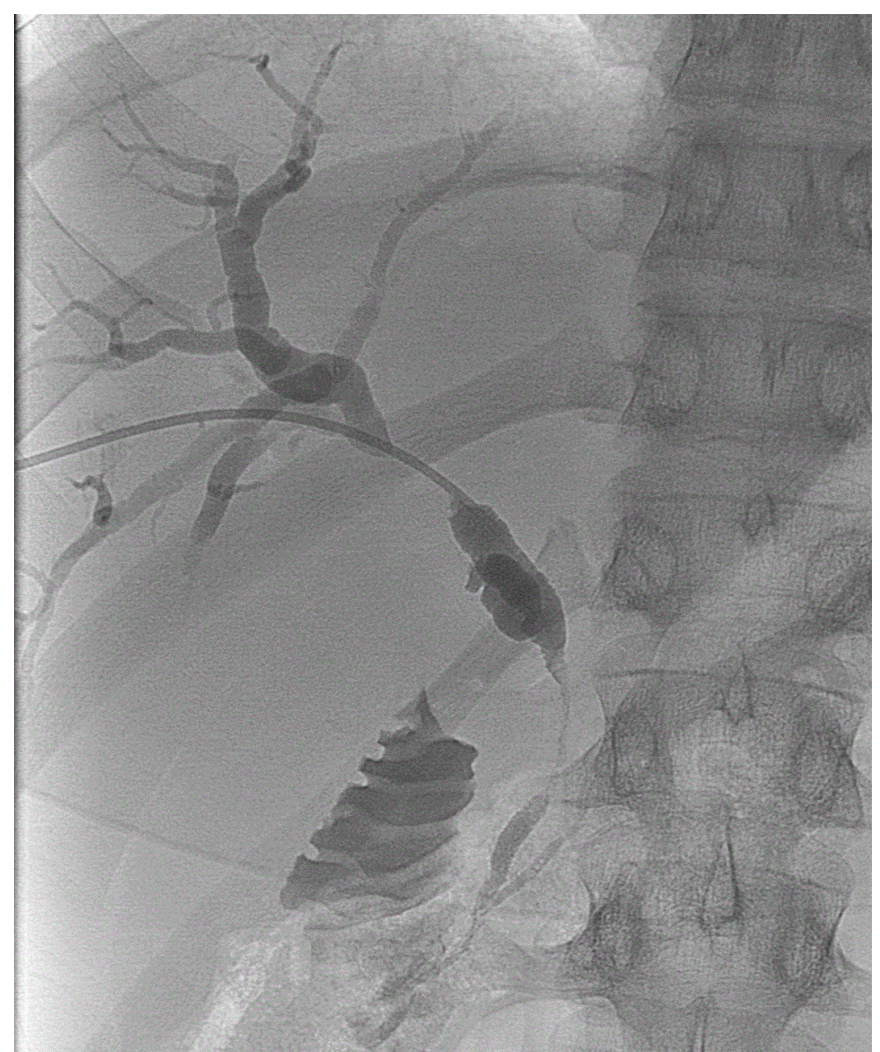

Figure 5 Cholangiogram: right percutaneous transhepatic cholangiogram drains.

The diagnosis of AML was made and was felt to be extremely unlikely that the biliary pathology represented a separate malignancy.

\section{TREATMENT}

The obstructive jaundice (bilirubin $251 \mu \mathrm{mol} / \mathrm{L}$, ALP 829U/L and ALT $605 \mathrm{IU} / \mathrm{L}$ ) was treated by interventional radiology with percutaneous transhepatic cholangiogram (PTC) of right duct system with subsequent cholangiography confirming a complex hilar stricture with no cross filling into the right posterior

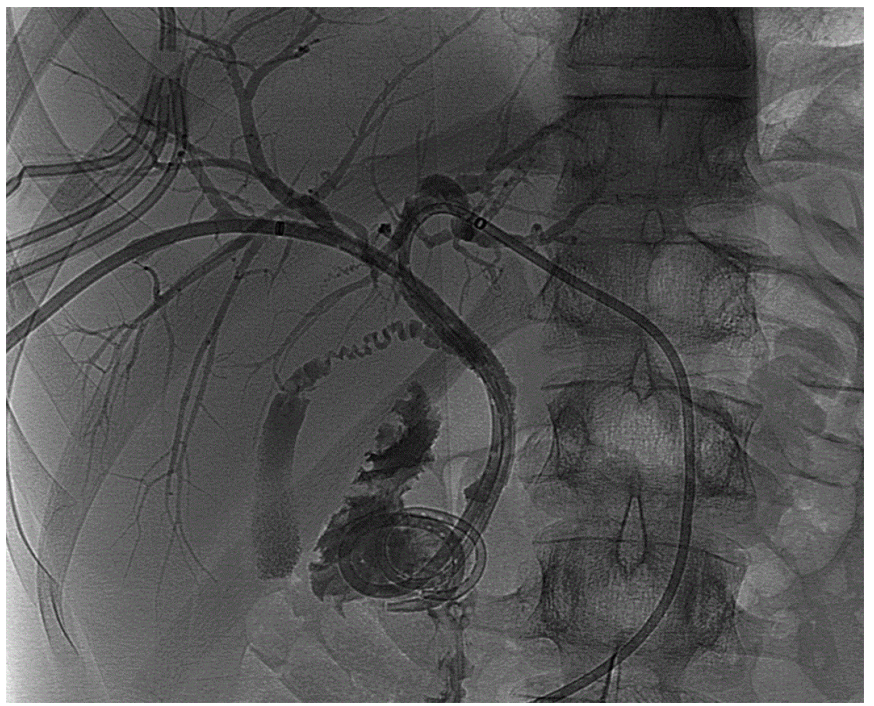

Figure 6 Cholangiogram: left and right percutaneous transhepatic cholangiogram drains.

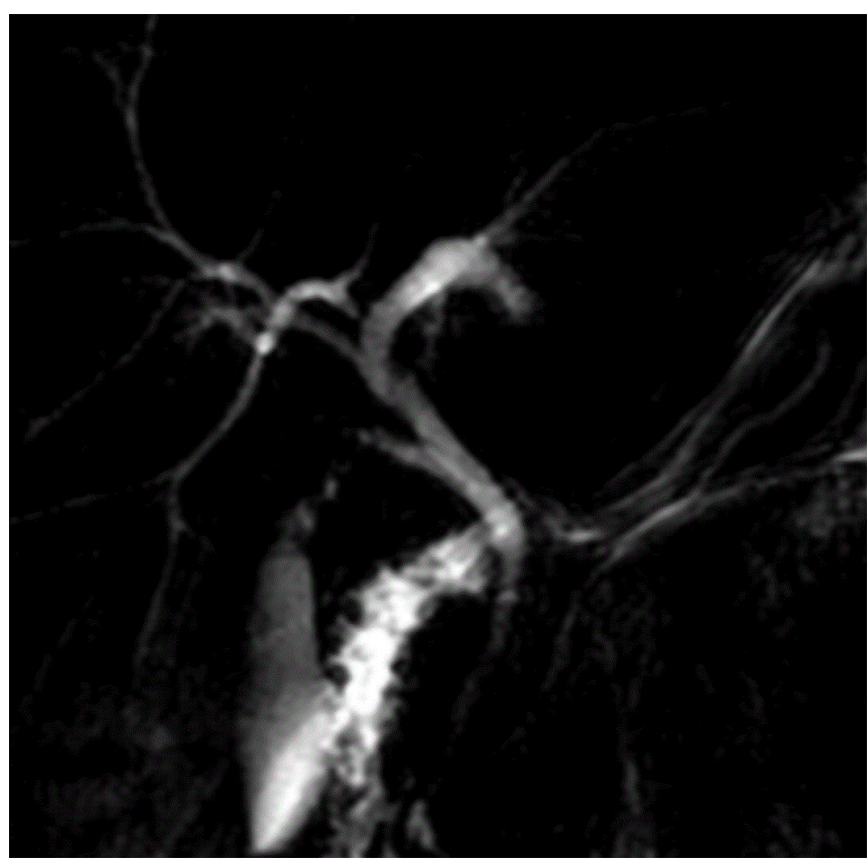

Figure 7 Post-treatment magnetic resonance cholangiopancreatography: resolution of multiple biliary duct strictures.

sectoral or left duct systems. A CBD stricture was also noted. Biliary drainage was achieved by the insertion of a 10.2F internal/ external drain into the right duct system (figure 5). Cytological examination of the biliary fluid was not performed.

Following right ductal PTC, a fall in serum bilirubin (bilirubin $134 \mu \mathrm{mol} / \mathrm{L}$, ALP $721 \mathrm{U} / \mathrm{L}$ and ALT $432 \mathrm{IU} / \mathrm{L}$ ) allowed initiation of chemotherapy with half dose daunorubicin to limit the hepatotoxicity and full dose of cytarabine. He had a further three cycles of high-dose cytarabine. The inv (16) chromosome abnormality was considered a good risk and an allograft was not indicated in the first remission.

After 3 weeks, serum bilirubin levels remained elevated $(52 \mu \mathrm{mol} / \mathrm{L})$, with persistent dilatation of the left duct system. Therefore, a left PTC with $10.2 \mathrm{~F}$ internal/externaldrain was sited and the right-sided drain replaced (figure 6) once the neutrophil count had recovered.

\section{OUTCOME AND FOLLOW-UP}

During the neutropenic phase, following the first cycle of chemotherapy, the bilateral PTCs were closed with internal drainage to mitigate the risk of sepsis. Despite this, the patient had two episodes of neutropenic sepsis with infection of the PTC drains. He responded well to antibiotics. The drains were changed regularly for 4 months, before being permanently removed following chemotherapy and radiological resolution of the biliary strictures.

Repeat bone marrow biopsy showed complete morphological and cytogenetic remission 4 weeks after the first cycle of chemotherapy.

The patient remained in remission following 4 cycles of chemotherapy. Follow-up MRCP in January 2016 showed significant improvement of the CBD and pancreatic duct strictures (figure 7) and normal liver function on his follow-up biochemistry.

At 2 years post diagnosis, there has been no relapse or progression on follow-up MRCP imaging and liver function tests remained normal. 


\section{DISCUSSION}

Obstructive jaundice has only rarely been observed as the presenting feature of AML, and only with small duct cholestatic features. ${ }^{1}$ It has been described in case reports as resulting from granulocytic sarcoma and leukaemic infiltration of the liver. ${ }^{2}$

\section{Learning points}

- This is a rare case of acute myeloid leukaemia (AML) presenting with obstructive jaundice.

- No evidence of hepatic infiltration was found on liver biopsy.

- Early percutaneous transhepatic cholangiogram and relief of biliary obstruction facilitated chemotherapy, resulting in remission of AML and radiological resolution of common bile duct strictures.

- The patient is in sustained remission after four cycles of chemotherapy with significant improvement of the intrahepatic and pancreatic ductal stricture.

- AML should be considered in the differential diagnosis of biliary strictures.
This is the first reported case of AML presenting with large bile duct strictures. Although we could not confirm direct AML invasion in the biliary tracts, there was a synchronous presentation of AML and biliary strictures and the strictures subsequently resolved with chemotherapy.

Contributors $A B$ acquired the clinical data and wrote the first draft of the report. $\mathrm{HH}$ interpreted the blood film and bone marrow data, provided clinical data and interpretation of findings. SJ provided the diagnostic and interventional radiology data and interpretation. DS conceived the report, wrote the final draft, provided interpretation of findings and literature review. All authors approved the final report.

Funding The authors have not declared a specific grant for this research from any funding agency in the public, commercial or not-for-profit sectors.

Competing interests None declared.

Patient consent for publication Obtained.

Provenance and peer review Not commissioned; externally peer reviewed

\section{REFERENCES}

1 Wandroo FA, Murray J, Mutimer D, et al. Acute myeloid leukaemia presenting as cholestatic hepatitis. J Clin Pathol 2004;57:544-5.

2 Ersbøll J, Petri J, Jensen $\mathrm{KH}$, et al. Granulocytic sarcoma preceding acute myeloid leukaemia. Scand J Haematol 1980;24:435-45.

Copyright 2019 BMJ Publishing Group. All rights reserved. For permission to reuse any of this content visit

https://www.bmj.com/company/products-services/rights-and-licensing/permissions/

BMJ Case Report Fellows may re-use this article for personal use and teaching without any further permission.

Become a Fellow of BMJ Case Reports today and you can:

- Submit as many cases as you like

- Enjoy fast sympathetic peer review and rapid publication of accepted articles

- Access all the published articles

- Re-use any of the published material for personal use and teaching without further permission

For information on Institutional Fellowships contact consortiasales@bmjgroup.com

Visit casereports.bmj.com for more articles like this and to become a Fellow 